\title{
DOCUMENTO
}

\section{O PLANO DE ENSINO DO GRÊMIO DE PROFESSORES PAULISTAS PARA A PRIMEIRA REFORMA DA INSTRUÇÃO PÚBLICA (1891) ${ }^{1}$}

\author{
THE EDUCATIONAL PROPOSAL OF THE ASSOCIATION PAULISTA TEACHERS \\ FOR THE FIRST REFORM OF PUBLIC INSTRUCTION (1891)
}

Lidiany Cristina de Oliveira Godoi

\section{Introdução}

\section{$\cos 8$}

um plano de ensino com a seguinte apresentação:

A comissão de professores publicos, encarregada da honrosa incumbencia de collaborar com a reforma da instruccão publica deste Estado, tem a subida honra de apresentar-vos o presente trabalho, tendo unicamente em vista auxilar-vos com algumas lembrancas, filhas de apurada observacão, de repetidas experiencias e pratica do ensino [...]. Confiado no vosso elevado criterio e alto patriotismo, o professorado espera ver em breve, em nosso Estado, escolas primarias, organisadas segundo o systema seguido pelos paizes mais adiantados, com as modificacões apenas que o vosso meio exige.(Plano de Ensino, 1891, p. 1). ${ }^{2}$

\footnotetext{
${ }^{1} \mathrm{~A}$ análise deste documento faz parte da pesquisa de doutorado intitulada $A$ primeira reforma da instrução pública paulista: consensos e disputas entre os diferentes sujeitos sociais (1892-1896), financiada pela Fundação de Amparo à Pesquisa do Estado de São Paulo.

2 Optou-se, neste excerto, por manter a grafia original do documento.
} 
O texto, com dezenove páginas, fora solicitado ao Grêmio de Professores da Escola Normal da Capital para ser encaminhado à futura Comissão de Instrução Pública do Congresso do Estado de São Paulo como sugestão para a reforma que modificaria, substancialmente, o ensino público em seus três níveis ${ }^{3}$. A ênfase do documento, no entanto, estava no ensino de nível primário, consoante ao pensamento defendido por professores, intelectuais e alguns políticos, que concentravam esforços para a disseminação da educação popular.

Este documento encontra-se no acervo do Arquivo Público do Estado de São Paulo, na Série Instrução Pública, Ordem 5014. É um documento raro e quase não referenciado nas pesquisas, além de ser um dos poucos do período que registram as proposições dos professores da Escola Normal no início dos debates que envolveram a reforma da instrução pública. Seus signatários são os professores Fernando Bonilha Junior, José Couto Junior, Pelopidas de Toledo Ramos, Faustino Ribeiro e Arthur Breves. O primeiro projeto para reforma da instrução pública entrou em debate na Câmara dos Deputados poucos meses depois, sendo apresentado pelo próprio Arthur Breves, eleito deputado e representante do interesse dos professores. Pode-se dizer que o magistério paulista procurava, naquele momento, afirmar-se como categoria profissional.

Como parte de um longo processo que vinha adequando-se às mudanças no cenário brasileiro desde meados do Império, a educação escolarizada tornava-se objeto de debates, de artigos na imprensa, de conferências diversas e assumia, em grande medida, certo valor social. As propostas para a primeira reforma do ensino acompanhavam um movimento encetado em vários países europeus e também nos Estados Unidos. A escolarização primária passava por considerável expansão, dada a importância do desenvolvimento técnico-científico impulsionado pela Revolução Industrial e a demanda por um maior uso social da leitura e da escrita. (Hobsbawm, 1988).

As propostas do Grêmio, elaboradas em forma de artigos, compreendiam a divisão de poderes na estrutura administrativa de ensino, o conteúdo que faria parte do currículo escolar e a organização do trabalho docente o que foi, em parte, incorporada à lei n. 88, de 8 de setembro de 1892. A participação dos professores no campo das políticas educacionais também levou a que suas propostas alçassem vôos maiores, para além da organização escolar, e tratassem, por exemplo, de melhorias em suas condições de trabalho. Algumas destas propostas possibilitaram significativo poder de decisão, outras, foram desconsideradas.

O documento elaborado pelo Grêmio de Professores pode ser importante para compreender os avanços de uma categoria profissional que tentava ampliar seu espaço de participação política e encontrava, ao mesmo tempo, limites impostos pelo governo na então nascente República brasileira.

\footnotetext{
${ }^{3}$ Lei n. 88, de 8 de setembro de 1892 - Reforma da Instrução Pública Paulista.
} 
Embora não fosse um consenso entre os republicanos paulistas ${ }^{4}$, a Constituição de 1891 manteve a obrigatoriedade do ensino primário, já instituída pela legislação provincial de 1887, lei n. 81, de 6 abril. Desde a última década do século 19, quando a reforma da Escola Normal da Capital foi confiada ao médico Caetano de Campos, os professores afirmavam-se como categoria profissional. Num momento em que a adoção do sufrágio universal exigia a alfabetização como condição para a participação política e também a tornava uma importante estratégia para divulgar a propaganda do regime republicano, os professores alcançaram certo prestígio, sentindo-se tão responsáveis pela educação quanto o governo.

Organizados em torno do Grêmio da Escola Normal, passaram a compreender seu ofício como uma missão. Embora não se saiba, com precisão, quantos membros compunham o Grêmio nesse período, não seria incorreto sugerir que pudesse ser representativo dos anseios de uma parte significativa dos professores. Vários relatórios de inspetores, professores e diretores, enviados ao diretor geral da Instrução Pública no período, revelam uma afinidade entre as concepções dos professores da Capital e as dos professores de diversos municípios do interior do Estado, especialmente àquelas voltadas a melhor organização do trabalho e salários.

O Plano de Ensino permite compreender algumas visões de educação compartilhadas pelos professores, bem como propostas que foram objeto de conflitos ou disputa entre os diferentes grupos políticos que participaram da reforma do ensino naquele momento. Convém destacar que muitas das propostas presentes no Plano foram retomadas pelo deputado Gabriel Prestes, em 1892, ao defender a concentração de esforços na instrução pública primária. O excerto apresentado no início deste texto destaca a importância que os docentes atribuíam ao seu próprio trabalho, pois as propostas apresentadas, segundo sua visão, estavam assentadas em anos de prática no exercício da docência e de suas observações no dia a dia escolar. Tentavam, naquele momento, adaptar o que liam a respeito dos modernos métodos de ensino de outros países à realidade do que observavam no trabalho, atentos aos movimentos da época.

Nas primeiras quatro páginas, uma espécie de preâmbulo, o enfoque centra-se na parte da divisão de poderes da nova organização do ensino. Um dos primeiros pontos abordados é o da necessidade de criação de um Conselho Diretor, o que, por sua vez, seria essencial para que se tomassem medidas de acordo com a realidade escolar e para que houvesse uma distribuição mais democrática de poderes. Distribuição que se estendia a todos os professores de todas as categorias, pois, de acordo com o terceiro parágrafo do artigo décimo, o inspetor de distrito deveria convocar os professores dos diversos municípios em assembléias, de modo a discutir modificações no programa de ensino e outras questões que fossem consideradas importantes.

\footnotetext{
${ }^{4}$ Embora os republicanos paulistas, ainda no decorrer do Império, reconhecessem a importância da educação para o desenvolvimento do país, não estava muito clara a questão da responsabilidade do Estado para com o ensino primário, uma vez que a intervenção do governo feria um dos princípios do liberalismo: a liberdade individual. O grupo de Campinas, segundo Moraes (2006), teria sido o primeiro a modificar seu posicionamento, colocar fim ao impasse ao optar pela obrigatoriedade do ensino primário e, com isso, arregimentar os demais membros do Partido Republicano. É importante destacar que os debates parlamentares que envolveram a reforma da instrução pública de 1892, revelam não haver consenso quanto à obrigatoriedade do ensino primário. Ver Anais da Câmara do Estado de São Paulo (1891, p. 371-823).
} 
As propostas contidas nas páginas dedicadas à organização do ensino foram as que estiveram mais próximas do modelo adotado na reforma do ensino e, embora tenha havido inúmeras discussões, debates e diferentes projetos que envolveram a elaboração da lei de 8 de setembro de 1892, esta expressa, em certa medida, o pensamento do professorado.

Reis Filho (1974), ao discutir a reforma da instrução pública, afirma que o Plano de Ensino enviado ao governador do Estado, embora representasse o pensamento dominante entre os líderes do magistério, não teria sido provido de nenhuma justificativa ou fundamentação. Opondo-se a esta idéia, acredita-se na importância do documento para aquele momento histórico. Não seria sem um propósito preciso que, logo na apresentação do Plano, o Grêmio de Professores afirmava sentir-se honrado da incumbência de colaborar com a reforma do ensino. O documento é enviado diretamente ao chefe máximo do Estado. Fora uma solicitação deste, o que sugere que a opinião dos professores era relevante.

Por fim, pode-se pensar que, num contexto mais amplo, o plano fornece elementos para uma melhor compreensão do significado da reforma da instrução pública de 1892 , bem como evidencia que esta estava distante de ser um consenso e que havia, no final do século 19 em São Paulo, diferentes visões de educação em disputa. Elucidativo de que a ação do Estado no campo das políticas públicas, entre elas, a educação, não era uma mão de via única, o documento mostra que os professores procuraram, à medida do possível, participar dos acontecimentos e das mudanças que marcaram a transição do século 19 para o século 20 , defender o que acreditavam ser fundamental para a educação da época e responder aos desafios do seu tempo.

\section{Referências}

1887. Lei n. 81, 6 de abril de 1887. Assembléia Legislativa dos Deputados do Estado de São Paulo. [On-line]. Disponível em: <http://www.al.sp.gov.br/norma?id=64259>. Acesso em: 5 jan., 2013.

1891. Instrução Pública. Plano de Ensino. Proposta da Comissão de Professores Públicos para a Reforma da Instrução Pública Paulista ao Governador do Estado de São Paulo, Jorge Tibiriçá (5 de janeiro de 1891). Arquivo Público do Estado de São Paulo. Ordem 5014.

1891. Anais Câmara de Deputados do Estado de São Paulo. Acervo Histórico da Assembléia Legislativa do Estado de São Paulo.

1892. Anais da Câmara de Deputados do Estado de São Paulo. Acervo Histórico da Assembléia Legislativa do Estado de São Paulo.

1882. Lei n. 88, de 8 de setembro de 1892. Diário Oficial. Assembléia Legislativa dos Deputados do Estado de São Paulo. [On-line]. Disponível em: <http://dobuscadireta.imprensaoficial.com.br/default.aspx?DataPublicacao=18920915\&Ca derno=Diario\%200ficial\&NumeroPagina=4101>. Acesso em: 15 dez., 2013.

1892. Instrução pública. Vocabulário da lei n. 88 de 1892. Arquivo Público do Estado de São Paulo. Ordem 0167.

1893. Lei $\mathrm{n}$. 169, de 13 de agosto de 1893. Diário Oficial. Assembléia Legislativa dos Deputados do Estado de São Paulo. [On-line]. Disponível em: 
<http://dobuscadireta.imprensaoficial.com.br/default.aspx?DataPublicacao=18930813\&Ca derno=Diario\%20Oficial\&NumeroPagina=7629>. Acesso em: 4 jan., 2013.

DEGANI, Maria Therezinha. Aspectos mais significativos da instrução no Estado de São Paulo na primeira década republicana. Araraquara: FFCL, 1973. 183f. Tese (doutorado em Educação). Faculdade Filosofia, Ciências e Letras de Araraquara.

HOBSBAWM, Eric. A era dos impérios 1875-1914. Rio de Janeiro: Paz e Terra, 1988.

MORAES, Carmen Sylvia Vidigal. O ideário republicano e a educação: uma contribuição à história das instituições. Campinas: Mercado das Letras, 2006.

REIS FILHO, Casemiro dos. A reforma republicana do ensino paulista. São Paulo: PUCSP, 1974. 277f. Tese (doutorado em Educação). Pontifícia Universidade Católica de São Paulo.

LIDIANY CRISTINA DE OLIVEIRA GODOI é estudante do curso de doutorado em História e Filosofia da Educação na Faculdade de Educação da Universidade Estadual de Campinas. Integra o Grupo de Estudos e Pesquisa História, Sociedade e Educação no Brasil.

Endereço: Caixa postal 22 - 13280-000 - Vinhedo - SP - Brasil.

E-mail: lidianygodoi@yahoo.com.br.

Recebido em 20 de março de 2013.

Aceito em 10 de abril de 2013. 


\section{PLANO DE ENSINO \\ PROPOSTA DA COMISSÃO DE PROFESSORES PÚBLICOS PARA A REFORMA DA INSTRUÇÃO PÚBLICA PAULISTA AO GOVERNADOR DO ESTADO DE SÃO PAULO, JORGE TIBIRIÇÁ.}

SÃo PAULO, 5 DE JANEIRO DE 1891.

A commissão de professores publicos encarregada de honrosa incumbencia de collaborar na confecção da refoma da instrucção publica deste Estado tem a subida honra de apresentar-vos o presente trabalho tendo unicamente em vista auxiliar-vos acom algumas lembranças, filhas de apurada observação, de repetidas experiencias e pratica de ensino.

Felizmente, já é mui consideravel o circulo de homens de talento, que se interessam pela educação popular, e foi com indizível satisfação que elles receberam a noticia do vosso procedimento.

Confiado no vosso elevado criterio e elevado patriotismo, o professorado espera ver em breve em nosso Estado, escolas primarias organisadas segundo o systema sugerido pelos paizes mais adiantados, com as modificações apenas que o nosso meio exige.

Neste systema, deve ser inscripto o que adoptou a Prussia: - liberdade em todos os gráos do ensino, menos no primário porque os pais têm o direito de escolher entre 0 ensino publico e o particular, mas não entre a educação e a ignorancia.

Relativamente á parte administrativa tres razões prevalecem para a creação de um conselho director.

Em materia administrativa é um principio universalmente reconhecido que o conselho e a deliberacão pertencem a muitos, ao passo que a aç̧ão deve ser de um só. Por outro lado, sendo tal conselhor eleito pelos professores, o governo fica ao abrigo de qualquer desgosto ou queixa que possa vir do professorado. Finalmente, é de extrema necessidade haver em nossa capital um corpo colletctivo, que se preocupe com os progressos do ensino em todos os paizes adiantados e impulsione, em nosso Estado, a instrucção popular, afim de se poder chegar á municipalização do ensino, do mesmo modo que pela obrigatoriedade da instrucção primaria se ha-de chegar á plena liberdade.

O Governador, na esphera do poder executivo, e o inspector geral, na esphera da fiscalização, exercem acção poderosa e benefica em todo o ensino.

$\mathrm{Na}$ creação de inspectores de districto, os professores obedeceram unicamente a um principio: - ninguem é mais competente para fiscalizar os trabalhos de uma profissão do que aquelle que por longos annos a exerceu.

Firmado que o ensino deve ser scientifico, comprehende-se que ele deve abranger o estudo do mundo, do homem e da sociedade, isto é, deve ser integral. Eis a razão por que as escolas foram divididas em tres gráos.

Dando a cada escola mais de um professor, baseou-se ainda a commissão no seguinte principio: - é impossível a um só indivíduo ensinar e fiscalizar ao mesmo tempo.

Assim, resultados philosoficos estabelecidos pelos maiores pensadores do nosso seculo, axiomas da sciencia administractiva e medidas suggeridas pela pratica do ensino, 
militam em favor do plano que a commissão vos apresenta, esperando do vosso patriotismo que seja realisado o pensamento do professorado, numa reforma de instrução digna da fórma de governo adoptada a 15 de Novembro.

Saude e Fraternidade.

Ao cidadão Doutor Jorge Tibiriçá, Governador do Estado de São Paulo.

São Paulo, 5 de Janeiro de 1891.

O presidente da Commissão [,] Fernando Bonilha Junior

O secretario - José N. Couto Junior

A commissão de redacção:

Arthur Breves [;] Pelopidas de Toledo Ramos[;] Faustino Ribeiro Junior.

Da direcção e fiscalização do ensino

Art. $1^{\circ}$. - A suprema direcção do ensino compete ao Governador do Estado.

Art $2^{\circ}$. - A direcção e fiscalização do ensino ficam a cargo de um conselho director, [de] um inspector geral e de inspectores de districtos, todos dignamente remunerados.

Do conselho director

Art $3^{\circ}$. - O conselho director, composto de tres membros, será eleito pelos professores de todas as cathegorias e directores de colegios.

$\S$ Unico. Podem fazer perte deste Conselho os professores publicos, que serão dispensados do exercicio das respectivas cadeiras emquanto durar o mandato.

Art $4^{\circ}$. - Ao conselho director compete:

$\S 1^{\circ}$. Propor ao congresso do Estado a creação e supressão de cadeiras;

$\S 2^{\circ}$. Propor ao Governador a nomeação, suspensão, demissão, aposentadoria, permutas e remoções dos professores;

$\S 3^{\circ}$. Orçar as despezas com a instrucção e submeter o orçamento á approvação do congresso;

$\S 4^{\circ}$. Dirigir as comissões incumbidas da construç̧ão de edificios escolares;

$\S 5^{\circ}$. Organisar o regulamento interno das escolas e prove-las de mobilia e apparelhos para o ensino intuitivo:

$\S 6^{\circ}$. Fornecer, por conta do Estado, livros, papel, tinta e outros utensilios necessarios ás escolas;

$\S 7^{\circ}$. Enviar aos professores as obras classicas de ensino, que forem apparecendo, e exigir delles a appreciação correspondente;

$\S 8^{\circ}$. Convocar annualmente os professores e expor-lhes os progressos do ensino;

$\S 9^{\circ}$. Providenciar no sentido de que os professores façam conferencias publicas sobre assumptos de instrucção;

$\S 10^{\circ}$. Tratar de tudo o que se refere ao fundo escolar. 
Art. $5^{\circ}$. A assistencia ás sessões do conselho é obrigatoria,e os membros que, sem motivo justificado, deixarem de comparecer, perderão os vencimentos correspondentes aos dias de falta.

$\S$ Unico. Os membros que, na fórma deste artigo, faltarem a cindo sessões consecutivas perderão o cargo.

\section{Do inspector geral}

Art. $6^{\circ}$. - O inspector geral será nomeado pelo governador.

Art. $7^{\circ}$. - É da sua exclusiva competencia:

$\S 1^{\circ}$. Inspeccionar, por si ou com auxilio do conselho director e dos inspetores de districtos, os estabelecimentos de ensino, assim publicos como particulares;

$\S 2^{\circ}$. Exercer todas as atribuições conferidas ao actual director de instrucção publica pela lei n. 81 de 6 de Abril de 1887, em tudo o que for compativel com o presente plano.

\section{Dos inspectores de districtos}

Art. $8^{\circ}$. - O Estado será dividido em districtos escolares, havendo em cada um delles um inspector.

Art. $9^{\circ}$. - Directamente a inspecção das escolas fica a cargo dos inspectores de districto.

$\iint$ Unico. Estes inspectores, tirados dentre os professores normalistas, serão nomeados pelo governo.

Art $10^{\circ}$. - Compete aos inspectores de districtos:

$\S 1^{\circ}$. Visitar cada estabelecimento de ensino ao menos uma vez por mez;

$\S 2^{\circ}$. Notar as necessidades das escolas e, por meio de um relatorio, leva-las ao conhecimento do conselho director;

$\S 3^{\circ}$. Reunir em assembléias os professores dos respectivos districtos para serem discutidas as modificações que julgarem necessarias no programma de ensino;

$\S 4^{\circ}$. Reunírem-se na Capital, no fim de cada anno lectivo, para, de accordo com as deliberações tomadas pelas assembléias de que trata o $\S$ antecedente, propor ao conselho director as modificações que forem julgadas necessarias;

$\S 5^{\circ}$. Conceder aos professores dos respectivos districtos até quinze dias de licença, por motivo justificado;

$\S 6^{\circ}$. Exercer todas as attribruições que são investidos os actuais conselhos municipaes, em virtude da lei n. 81 de 6 de Abril de 1887, que não forem incompatíveis com o presente plano.

Dos professores publicos

Art. $11^{\circ}$. - Os professores não normalistas ficam equiparados a uma só cathegoria, com a denominação de professores de $1^{\circ}$. gráo. 
Art $12^{\circ}$. - Todo professor formado pela escola normal, que requerer provimento em cadeira de $1^{\circ}$. gráo, será nomeado, independentemente de outros documentos, alem do diploma da referida escola.

Art $13^{\circ}$. - As nomeaçõesde professores para as escolas de $2^{\circ}$. e $3^{\circ}$. gráo serão feitas por accesso, estabelecido de accordo com as seguintes disposições:

$\S 1^{\circ}$. Os professores que contarem cinco annos de exercicio em escola de $1^{\circ}$. gráo serão considerados habilitados a reger escola de $2^{\circ}$. gráo.

$\S 2^{\circ}$. Os que tiverem quatro annos de exercicio em escola de $2^{\circ}$. gráo serão habilitados a reger escola de $3^{\circ}$. gráo.

Art. $14^{\circ}$. - O exercicio a que se refere o artigo antecedente será contado sem as interrupções motivadas por licenças.

Art. $15^{\circ}$. - É livre aos professores o direito de remoção e permuta entre cadeiras de igual cathegoria, em relação aos tres gráos do ensino.

$\S 1^{\circ}$. No caso de remoção ou permuta, o motivo allegado pelo professor será attestado pelo respectivo inspector de distrito.

$\S 2^{\circ}$. Será indifferente estar ou não em effetivo exercicio.

Art. $16^{\circ}$. - O professor em goso de licença, em caso algum perceberá a gratificação.

Art $17^{\circ}$. - O professor eleito pelo voto popular não perderá o cargo: apensa será dispensado do exercício emnquanto durar ou não resignar o mandato.

Art. $18^{\circ}$. - Si o professor nomeado parta o cargo de inspector de districto estiver em exercício, sua cadeira passará a se regida por um substituto nomeado pelo inspector geral, até que elle seja dispensado do referido cargo.

Art $19^{\circ}$. - Nas escolas onde houver dois ou mais professores, um delles, por nomeação do governo, exercerá cumulativamente as funcções de director do estabelecimento.

Art. $20^{\circ}$. - O professor adjunto exercerá o cargo de secretario da escola.

Art $21^{\circ}$. - Quando uma cadeira for suprimida por qualquer circumstancia, o professor respectivo será provido em outra á sua escolha, observada sempre a igualdade de cathegoria.

$\S$ Unico. No caso de não requerer provimento em outra cadeira dentro de trinta dias, será privado do vencimento.

Das escolas, sua organisação e programma de ensino

Art. $22^{\circ}$. - Fica decretado o ensino primario obrigatorio por espaço de dez annos, podendo o governo prolongar este praso, caso julgue conveniente.

Art. $23^{\circ}$. - Todo o patrão ou chefe industrial, que tiver crianças ao seu serviço, será obrigado, sob pena de multa, que a lei estabelecerá, a dispensa-las do trabalho durante o tempo necesario para frquentarem as escolas.

Art. $24^{\circ}$. - O ensino é leigo e gratuito, observando-se nas escolas o programa estabelecido, com liberdade de exposição e methodo.

Art. $25^{\circ}$. - $O$ ensino particular é livre, devendo, porêm estar sujeito ás restrições que a lei determinar. 
Art. $26^{\circ}$. - Haverá no Estado de São Paulo escolas de $1^{\circ}$., $2^{\circ}$. e $3^{\circ}$. gráo, providas por professores normalistas e adjunctos.

Art. $27^{\circ}$. - Em toda e qualquer localidade onde houver trinta familias existirá uma escola de $1^{\circ}$. gráo, que será regida unicamente por um professor.

Art. $28^{\circ}$. - Nas freguezias, capellas e bairros populosos as escolas serão ragidas po um professor e um adjuncto.

$\S$ Unico. A base para a creação destas escolas será de cincoenta famílias.

Art. $29^{\circ}$. - Em toda localidade de dupla importancia existirá uma escola de $2^{\circ}$. gráo.

Art. $30^{\circ}$ - Nas cidades principais haverá escolas de $1^{\circ}$., $2^{\circ}$. e $3^{\circ}$. gráo, que funccionarão em um só prédio, com a denominação de - escolas-lyceus.

$\S$ Unico. O numero destas escolas será determinado pela cifra da população em geral e não da população escolar.

Art. $31^{\circ}$. - Nas localidades a que se referem os dois artigos antecedentes, as escolas de $1^{\circ}$. gráo serão regidas por dois professores e um adjuncto, e as de $2^{\circ}$. e $3^{\circ}$. gráo, por tres professores.

Art. $32^{\circ}$. - Podem ser professores adjunctos os professores normalistas, os não normalistas e os alumnos approvados nas materias do $2^{\circ}$. anno da escola normal.

Art. $33^{\circ}$. - As escolas não poderão ser removidas; serão supprimidas desde que desappareça a base para a criação dellas.

Art. $34^{\circ}$. - Nas escolas de $1^{\circ}$. gráo só poderão ser admitidos á matricula alumnos maiores de 7 e menores de 16 annos.

Art. $35^{\circ}$. - Nas escolas de $2^{\circ}$. e $3^{\circ}$. gráo só poderão matricular-se alumnos ate a idade de 17 annos, e serão eliminados, uma vez completos os 18 annos.

Art. $36^{\circ}$ - Nos logares onde não possa existir uma escola para cada sexo serão creadas, sob proposta do inspectores de districtos, escolas mixtas, que serão regidas por professores.

Art. $37^{\circ}$. - Em cada localidade, onde houver escolas de $1^{\circ}$. e $2^{\circ}$. gráo, ou escolaslyceus, haverá uma aula nocturna para adultos, em que serão leccionadas as materias do $1^{\circ}$. gráo, excepto gymnastica e musica.

$\S 1^{\circ}$. Só serão admittidos á matricula nestas aulas alumnos maiores de 16 annos.

$\S 2^{\circ}$. Não extenda a estas aulas obrigatoriedade do ensino.

Art. $38^{\circ}$. - As aulas nocturnas serão regidas por professores de $1^{\circ}$. gráo, que perceberão, alem dos vencimentos, mais uma gratificação.

Art. $39^{\circ}$. - As escolas, quer de $1^{\circ}$. , $2^{\circ}$. ou $3^{\circ}$. gráo, serão dividas em tres secções, comprehendendo as do $1^{\circ}$. gráo os estudos preliminares; as do $2^{\circ}$. gráo, o estudo do mundo; e as o $3^{\circ}$. gráo, o estudo do homem e da sociedade.

$$
1^{\circ} \text {. gráo }
$$

$1^{\text {a. }}$. secção. - Leitura elementar (classificação das vozes e das articulações, syllabas, dipthongos, acccento prosodico); leitura corrente (uso do diccionario, partes da oração, sem grammatica, conhecer os signaes da pontuação); leitura expressiva (construcção de um vocabulario, regras geraes de syntaxe, exposição sem o livro, da lição estudada). 
$2^{\mathrm{a}}$. secção. - Calligraphia (bastardo, bastardinho e cursiva); orthographia (cópia e dictado); redacção (de phrases, bilhetes, cartas e contos).

$3^{a}$. secção. - Numeração, quatro operações, desenho elementar de figuras, noções de musica, gymnastica.

$$
2^{\circ} \text {. gráo }
$$

$1^{\text {a }}$. secção. - Calculo arithmetica, takymetria (medida das linhas, das superficies e dos volumes); noções sobre forças e movimentos.

$2^{\circ}$. secção. - A Terra considerada em sua superficie (denominações dadas a todas ás terras e ás aguas, noções sobre o reino vegetal considerado em geral e sobre a flora paulista em especial), a terra considerada em sua atmosphera (metheóros, aquosos, aéreos, igneos), a terra em seu interior (fogo central, rochas, camadas geologicas).

$3^{\circ}$. secção. - Systema planetario considerado quanto á sua fórma, movimento e natureza physica; lições de cousas.

$$
3^{\circ} \text {. gráo }
$$

$1^{\text {a }}$. secção. - O esqueleto, as viceras (orgams alojados no craneo, no Thorax e no abdomen); os phenomenos da mastigação, da digestão, da circulação, da respiração, da assimilação e da secreção).

$2^{a}$. secção. - A alma (as funcções cerebraes); o homem em relação com os outros animaes (as escala zoologica).

$3^{\text {a }}$. secção. - A familia (deveres dos irmãos, dos filhos, dos conjuges, dos paes, phases por que passa a familia); A Pátria (a Constituição, noções dos codigos civil, criminal, comercial e militar, biographia dos brazileiros celebres, noticias geographicas e historicas do Brazil colonial sob Pedro II, historico da proclamação da República); a Humanidade (noticias geograficas e historicas sobre a America desde a descoberta até nossos dias, sobre a Europa considerada no regimen das conquistas, das guerras defensivas e da industria, sobre outras partes do globo, biografia dos occidentaes notaveis).

Art. $40^{\circ}$. - Nenhum alumno poderá matricular-se nas escolas de $2^{\circ}$. e $3^{\circ}$. gráo sem que prove estar habilitado nos de gráo immediatamente inferior.

Art. $41^{\circ}$. - O attestado de approvação plena nas materias do $3^{\circ}$. gráo habilita o alumno a ser nomeado, independentemente de concurso, para qualquer logar de praticamente das repartições publicos do Estado.

\section{Das despezas com a instrução}

Art. $42^{\circ}$. - O governo marcará o ordenado dos professores publicos, davendo ter em vista a melhoria dos vencimentos, afim de garantir-lhes a necessaria independencia na posição social que occupam. 
$\S 1^{\circ}$. No fim de dez annos de exercicios, o professor perceberá mais a quarta parte dos vencimentos.

$\S 2^{\circ}$. No fim de quinze annos peceberá mais a terça parte.

$\S 3^{\circ}$. No fim de vinte annos, perceberá mais a metade.

Art $43^{\circ}$. Por occasião da aposentadoria, todas essas partes serão contadas.

Art. $44^{\circ}$. Os professores receberão seus vencimentos nas collectorias de rendas do Estado, salvo quando lhes convenha recebe-las no Thesouro.

Art. $45^{\circ}$. Os professores não normalistas, que estiverem cursando a escola normal, perceberão os respectivos ordenados.

$\S 1^{\circ}$. O governo determinará o mumero de professoes que deverão matricular-se annualmente, sendo observada a ordem de antiguidade.

$\S 2^{\circ}$. Quando estes professores recusarem-se á matricula, serão privados das respectivas cadeiras e nomeados os adjunctos.

Art. $46^{\circ}$. - Fica creado um monte-pio obrigatorio para os funcionarios da instrucção publica.

Art. $47^{\circ}$. - O governo lançará um imposto ou taxa addicional sobre quaisquer impostos já existentes cujo producto reverterá em beneficio da instrucção publica primaria.

\section{Disposições gerais}

Art. $48^{\circ}$. - Todo o empregado da instrucção pública só poderá ser demitido em virtude de processo administrativo.

Art. $49^{\circ}$. - O cargo de qualquer funcionario da instrucção publica é incompativel com qualquer outra profissão, excepto o ensino particular.

Art. $50^{\circ}$. - As disposições deste plano serão applicadas a todas as escolas publicas de ambos os sexos, em tudo o que ellas tenham de commum, e as palavras - professor e adjuncto - comprehendem os mestres e mestras de qualquer categoria ou gráo.

Art. $51^{\circ}$. - Emquanto o governo não dotar as escolas de edificios proprios, alugará casas que tenham salas bem arejadas e possam comportar as diversas classes escolares.

$\S$ Unico. Antes de serem organisadas de acordo com estas bases, as escolas não deverão funccionar.

Art. $52^{\circ}$. - O governo tratará logo de organisar, na capital e nas cidades principaes, as escolas-lyceus, que funcionarào em um só predio.

Art. $53^{\circ}$. - As primeiras nomeações para as cadeiras de $2^{\circ}$. e $3^{\circ}$. gráo, que deverão recahir em professores formados pela escola normal, serão feitas livremente pelo governo.

Art. $54^{\circ}$. - O governo estabelecerá as penas, processos para a sua imposição e recursos, para a boa execução da reforma. 